\title{
An Elementary Review on Principles and Applications of Modern Non-Conventional Food Processing Technologies
}

\author{
Sheshrao Kautkar ${ }^{1 *}$ and Jai Prakash Pandey ${ }^{2}$ \\ ${ }^{1}$ Department of FM\&PHT, ICAR-Indian Grassland and Fodder Research Institute, \\ Uttar Pradesh-284003, India \\ ${ }^{2}$ Department of PHP\&FE, G. B. Pant University of Agriculture and Technology, \\ Uttarakhand-263145, India \\ *Corresponding author
}

\begin{tabular}{|c|}
\hline Keywords \\
\hline $\begin{array}{l}\text { Non-conventional } \\
\text { technologies, Ohmic } \\
\text { heating, Microwave } \\
\text { heating, High pressure } \\
\text { processing, Pulse electric } \\
\text { field, Pulsed light } \\
\text { technology and } \\
\text { ultrasound }\end{array}$ \\
\hline Article Info \\
\hline $\begin{array}{l}\text { Accepted: } \\
10 \text { April } 2018 \\
\text { Available Online: } \\
10 \text { May } 2018\end{array}$ \\
\hline
\end{tabular}

\section{Introduction}

In the modern era of food quality, safety, security and global warming, the responsibility is there on the shoulder of food processing industries to produce the food which satisfies consumer needs with keeping
Post-harvest processing and value addition is the most important aspect related to all the food products. Processing of agricultural commodities means converting the raw food material in to consumer acceptable form with increased shelf life and maintained nutritional quality. It can be achieved through various conventional food processing methods like drying, dehydration, evaporation, extrusion, freezing etc. The main lacunae with these conventional methods are loss of colour, flavour, vitamins and other nutrients due to higher temperature and longer processing time. These methods also causes problems like fouling on heating surface, energy inefficiency and emission of combustion gases in to the atmosphere leading to atmospheric pollution. The non-conventional food processing technologies like ohmic heating, microwave heating, ultrasound, pulsed electric field and high pressure processing are modern processing and preservation methods, rising as green technologies in food processing sector which represents environmental impact in terms of energy efficiency, water savings and reduced pollution. These technologies can produce high quality products with improvements in terms of heating efficiency, energy savings, reduced time and processing costs. All these technologies have wide range of applications in food industry like pasteurization, sterilization, oil extraction, juice extraction, clarification, filtration, cooking, baking, blanching, evaporation, drying, and dehydration. A comprehensive review is made to study the working principles, equipments, applications, advantages and limitations of these processing methods for used in various food product development and preservation operations. 
heated, by combustion of fuels or by an electric heated. These methods degrade the nutritional value of the product because of large extent of heat. Also considerable losses of heat on the surfaces of the equipment and installations, reduces the heat transfer efficiency of the processing method. Therefore in order to maintain food quality, microbial safety, to increase working life of equipments and heat transfer efficiency and to reduce atmospheric pollution we have to adapt some modern food processing technologies that can efficiently replace the conventional thermal food processing methods (Vicente and Castro, 2007). Ohmic heating and microwave heating are emerging alternatives to conventional methods of heat processing which generate heat directly inside the food products without using any external heating surface. These methods maintain nutritional quality of the product, reduces processing time with increased energy and heating efficiency than conventional methods. Now days, non-thermal technologies such as ultrasounds, high pressure processing, pulsed electric fields and pulsed light treatment have also been utilized for manufacturing of food products. These technologies has the ability to inactivate microorganisms, spores, enzymes and bacteria's at reduced temperatures and hence preserves the sensory and nutritional quality of products (Stoica et al., 2013). A comprehensive review is made to provide the basic information of these modern nonconventional thermal and non-thermal technologies in order to understand their working principles, equipments, applications, advantages and limitations.

\section{Ohmic heating $(\mathrm{OH})$}

\section{Principle of ohmic heating}

Ohmic heating is also called as "electrical resistance heating", "joule heating", or electro conductive heating" (Varghese et al., 2012). It is a simple food processing technique in which alternating electric current (AC) is passed through liquid or liquid-particulates foods primarily for heating. Heat generation is based on the principle that most food products have the ability to resist to the passage of an electrical current due to the electrical resistance of the food products. AC voltage is applied to the electrodes at both ends of the product body as shown in Figure 1 which cause internal energy generation within the food material. The most important factor in $\mathrm{OH}$ is electrical conductivity (EC) which is materials ability of how efficiently it flow electric current through it (Sakr and Liu, 2014) and its temperature dependence (Legrand et al., 2007). The EC is the ratio of the current density to the electric field strength and its SI unit is Siemens per meter $(\mathrm{S} / \mathrm{m})$. It increases with increasing temperature, which means $\mathrm{OH}$ becomes more effective as temperature increases (Kautkar et al., 2015). Absence of any external heating part makes it useful to avoid the thermal degradation of the product and keeps products quality basically intact.

\section{Equipment and applications}

The main components of $\mathrm{OH}$ system consist of electrodes, heating chamber and AC supply as shown in Figure 1 (Kautkar et al., 2016). It consists of other accessories like lid, control panel, stand, and voltmeter and ampere meter. The heart of $\mathrm{OH}$ system is two stainless steel electrodes and the function of these electrodes is to pass the electric current from the source of power supply to the food to be heated, the heating chamber is the place where food product is kept for heating, alternating current power supply is given to provide current to the system. This technology has wide range of applications in processing and used by various researchers for rice bran stabilization and oil extraction (Lakkakula et al., 2004), blanching (Icier et al., 2006), dehydration, evaporation (Assiry, 2011), juice extraction, peeling 
(Ngasri and Sastry, 2016), thawing (Duygu and Umit, 2015) fermentation, sterilization, pasteurization etc. (Knirsch et al., 2010; Kautkar et al., 2014).

Fig.1 Ohmic heating

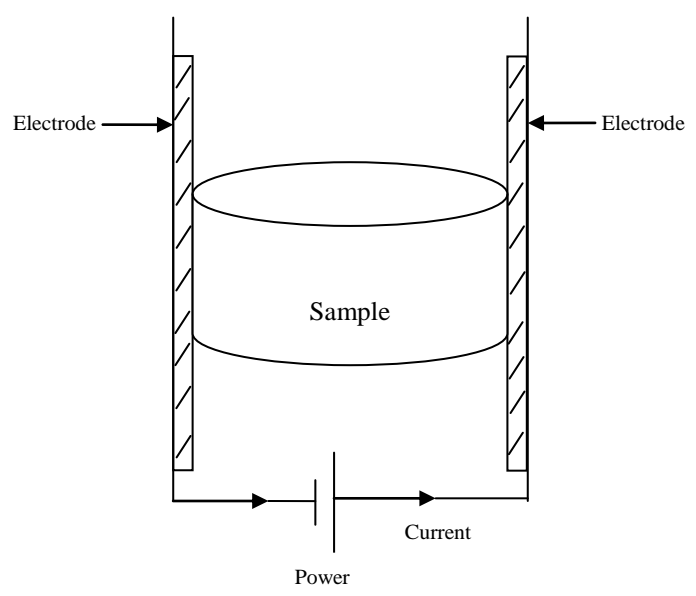

\section{Advantages and limitations}

$\mathrm{OH}$ has many advantages to be used in the food industries like uniform heating, high energy efficiency, reduced risks of fouling of heat transfer surface and burning of the food, higher temperature in shorter time can be achieved, suitable for both batch as well as continuous process, no residual heat transfer after the current is shut off, ease of process control with instant switch-on and shut-down and eco-friendly processing (Sakr and Liu, 2014). Limiting factors of using $\mathrm{OH}$ consist of unsuitability for solid or dry foods and requirement voltage adjustments according to the electrical conductivity of the foods.

\section{Microwave heating}

\section{Principle of microwave heating}

Microwaves are electromagnetic waves which have frequency range between $300 \mathrm{MHz}$ and $3000 \mathrm{MHz}$ corresponding to wavelength from $1 \mathrm{~mm}$ to $1 \mathrm{~m}$. Microwave frequencies of 915 $\mathrm{MHz}$ and $2450 \mathrm{MHz}$ can be utilized for industrial, scientific, and medical applications (Bradshaw et al., 1998). Food products have water molecules inside them which are dipolar in nature with one positively charged and other negatively charged end. These dipoles will orient themselves when they are subject to electromagnetic field. Once microwave energy is absorbed by food material, polar molecules such as water will rotate according to the alternating electromagnetic field. The rotation of water molecules is very rapid and about 24 billion times per second (Hill and Ilsi, 1998). This rapid orientation and reorientation of water molecule causes huge friction and hence a high amount of heat is generated inside of product. In addition to the dipole water molecules, ionic compounds (i.e. dissolved salts) in food can also be accelerated by the electromagnetic field and collided with other molecules to produce heat (Buffler, 1993).

\section{Equipment and applications}

The microwave heating system mainly consists of magnetron, wave guide, microwave cavity, fan, stirrer and turntable as shown in Figure 2. The magnetron is a diodetype electron tube which generates required $2450 \mathrm{MHz}$ of microwaves. Microwave cavity is a space inside which the food is kept for heating. Waveguide is the passage used to pass the microwaves from magnetron to cavity. The function of stirrer and turntable is to pass the microwaves to each corner of cavity and to rotate the food so that microwaves can uniformly apply on it (Puligundla et al., 2013). Microwaves have numerous applications in food processing which includes sterilization, pasteurization (Al-Hilphy and Ali, 2013), drying (Lule and Koyunchu, 2015), blanching (Ramesh et al., 2002), baking (Al-Muhtaseb et al., 2013), cooking (Zhang and Hamauzu, 2004), thawing, boiling etc. 
Fig.2 Microwave heating

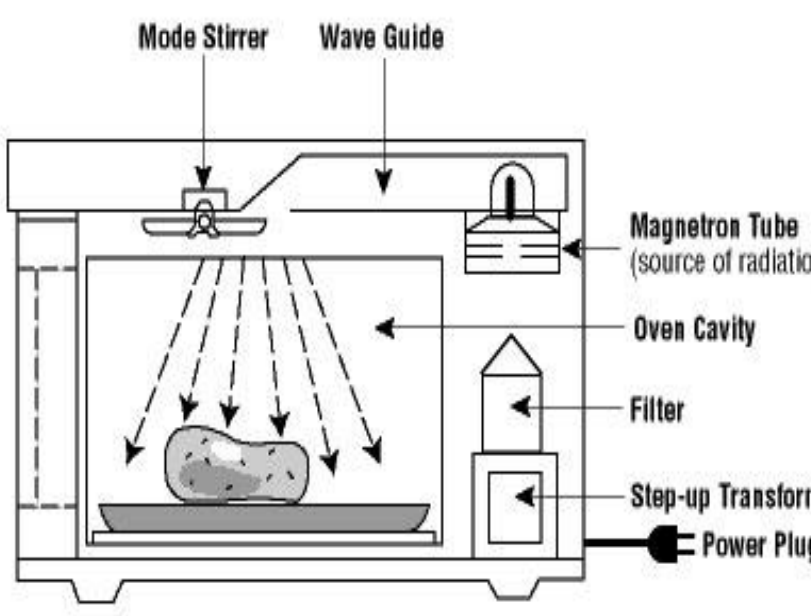

product placed between a pair of electrodes (Reddy and Penchalaraju, 2014). The large field intensities are achieved through storing a large amount of energy in a capacitor bank from a direct current power supply, which is then discharged in the form of high voltage pulses (Zhang et al., 1995). The pulse caused by the discharge of electrical energy from the capacitor is allowed to flow through the food material for an extremely short period of time (1-100 $\mu \mathrm{s})$ and can be conducted at moderate temperatures for less than $1 \mathrm{sec}$ (Deeth et al., m007). When food is subjected to the electrical high-intensity pulses, several events, such as resistance heating, electrolysis and electroporation can occur contributing to the inactivation of microorganisms (Sitzmann, 1995).

\section{Advantages and limitations}

Microwave heating possesses many advantages which include rapid and uniform heating, high heating efficiency i.e. $80 \%$ of the energy can be converted into heat, reduced loss of nutrients, minimum fouling depositions, suitable for heat-sensitive, highviscous, and multiphase fluids, do not generates exhaust gases therefore food does not contaminates by products of combustion, equipment is small, compact, clean in operation and automatic process control. Lower penetration depth, higher initial cost, non uniform heating when using large size product are some of the limitations of this method.

\section{Pulsed electric field (PEF)}

\section{Principle of pulsed electric field}

Pulsed electric field or "high intensity pulsed electric field" is a novel non thermal food processing method used to inactivate the deteriorative microorganisms with minimal effects on the nutritional, flavour and functional characteristics of food products. It is based on the application of pulses of high voltage typically $20-80 \mathrm{kV} / \mathrm{cm}$ passed on the
Fig.3 Pulsed electric field

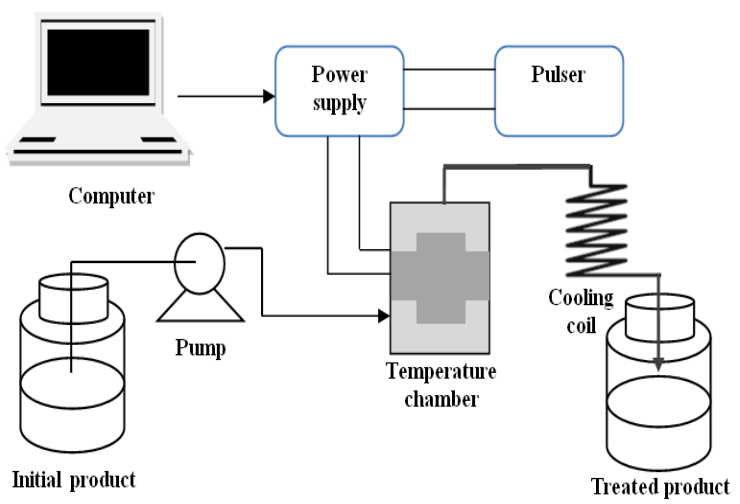

\section{Equipment and applications}

Typical PEF system consists of a high-voltage power supply, capacitors to store the charge, a discharge switch to release the charge to electrodes and a pump to force the liquid product from feed tank to treatment chamber as shown in Figure 3. The gap between two electrodes is called as the treatment gap. This technology is mainly used for preservation of pumpable fluid or semi-fluid foods and it has many applications in food industry for liquid foods which includes pasteurisation and extraction of fruit juices (Korma et al., 2016), 
soups, liquid egg (Nieto et al., 2003) and milk (Hawa et al., 2011), decontamination of heat sensitive foods (Zhao et al., 2008).

\section{Advantages and limitations}

This novel food processing method is widely used to kill vegetative cells, to preserve colour, flavour and nutrients of the product without any toxicity and to process the food in relatively short treatment time. The lacunae associated with this method are it is difficult to use with conductive materials, no effect on enzymes and spores, suitable for liquids or particles in liquids only and products of electrolysis may adversely affect foods.

\section{High pressure processing (HPP)}

\section{Principle of high pressure processing}

High pressure processing is also called as "ultra-high-pressure processing" (UHP) or "high-hydrostatic pressure processing" As the name suggests it utilizes high pressure to process the food product (Muntean et al., 2016). This is a promising non-thermal method of food preservation which efficiently inactivates the vegetative microorganisms, most commonly related to food borne diseases (Elamin et al., 2015). When high pressures, up to $1000 \mathrm{MPa}$ are applied to food packages submerged in a liquid, the pressure is distributed rapidly and uniformly throughout the food. The high pressure causes destruction of microorganisms (Rendueles et al., 2011). Vegetative microbial cells can be destroyed or deactivated by application of moderately high pressures in the range of $300-600 \mathrm{MPa}$. Typically, a pressure of $350 \mathrm{MPa}$ applied for $30 \mathrm{~min}$ or $400 \mathrm{MPa}$ applied for $5 \mathrm{~min}$ will cause a ten-fold reduction in vegetative cells of bacteria, yeasts or moulds (Hoover et al., 1989). The principle behind this technology is that the high pressure is applied in an "isostatic" manner such that all regions of food experience a uniform pressure, unlike heat processing where temperature gradients are established.

\section{Equipment and applications}

Typical HPP equipment consists of a pressure vessel, its closure, a pressure generating device, a temperature controlling device and materials handling system as shown in Figure 4 (Yordanov and Angelova, 2010). Food packages are submerged in to the vessel and the top is closed.

The pressure transmitting medium usually water is pumped into the vessel from the bottom. Once the desired pressure is achieved, the pumping is stopped, valves are closed and pressure can be maintained without further need for energy input.

HPP can effectively used in pasteurization and sterilization of fruits and vegetables (Hite et al., 1914), milk (Hite, 1899), sauces, pickles, yoghurt, pasteurization of meat (Campus, 2010), decontamination of high risk products, high value products and sterilization of heat sensitive ingredients like shellfish, flavourings, and vitamins.

Fig.4 High pressure processing

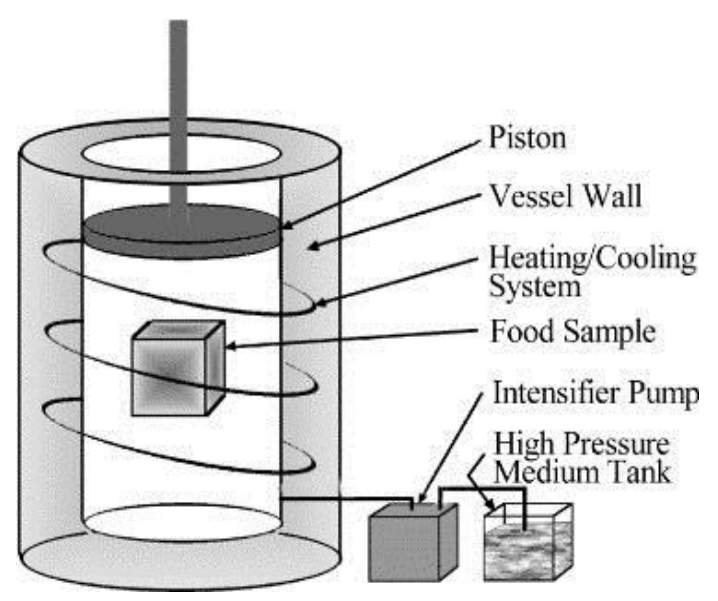




\section{Advantages and limitations}

HPP is effective in killing vegetative bacteria and spores without generating any toxicity, maintains nutritional quality, reduced processing time, uniformity of treatment, inpackage processing and it has potential for reduction or elimination of chemical preservatives. Some of the limitation of this method are it is the batch process and imparts little effect on enzyme activity, few microbial survival, expensive equipment and foods should have approximate $40 \%$ free water for anti-microbial effect.

\section{Pulsed light technology}

\section{Principle pulsed light technology}

Pulse light technology (PL), also called as "high intensity light" is a non-thermal decontamination or sterilization method that can be used for rapid inactivation of microorganisms from food surfaces, equipments and packaging materials. It contains a broad spectrum of white light, from ultra violet (UV) wavelengths of $200 \mathrm{~nm}$ to infra-red (NIR) wavelengths of $1000 \mathrm{~nm}$ with peak emissions between 400-500 nm (Yasothai and Giriprasad, 2015). Pulses of light used for food processing applications typically emit 1-20 flashes per second of electromagnetic energy. The basic principle of light at UV wavelengths is its photochemical and/or photothermal effects (Elmanesser et al., 2007; Gomez-Lopez et al., 2007) which exhibits its antimicrobial nature.

The photochemical mechanism alters the structure of pyrimidine bases and DNA (Giese and Darby, 2000), leading to the death of the microorganisms (McDonald et al., 2000). The photothermal effect is due to the conversion of UV photons into energy, causing a short, sharp, local temperature rise at the surface of the target (Whekof, 2000). When energy from
UV wavelengths is absorbed by highly conjugated double carbon bonds in proteins and nucleic acids then several mechanisms like structural changes in the DNA, abnormal ion flow, increased cell membrane permeability and depolarization of the cell membrane occurs in the targeted material which leads to rapid inactivation of microorganisms (Abida et al., 2014).

\section{Equipment and applications}

PL technology consists of a flash lamp, power supply unit and a treatment chamber as shown in Figure 5. The PL unit which is a flash lamp filled with an inert gas, such as Xenon, emits broadband radiation that ranges from the UV cut off to NIR (Dunn et al., 1989) A highvoltage, high-current electrical pulse is applied to the inert gas in the lamp, and the strong collision between electrons and gas molecules cause excitation of the gas molecules, which then emit an intense, very short light pulse. This technology is used in decontamination of vegetables, dairy products (Yeom et al., 2004), baked products, fruit beverages (Sharma et al., 1998), meats and seafood's, drying and decontamination of, microbial inactivation of water, sanitation of packaging materials and disinfection of equipment surfaces (Abida et al., 2014).

Fig.5 Pulsed light technology

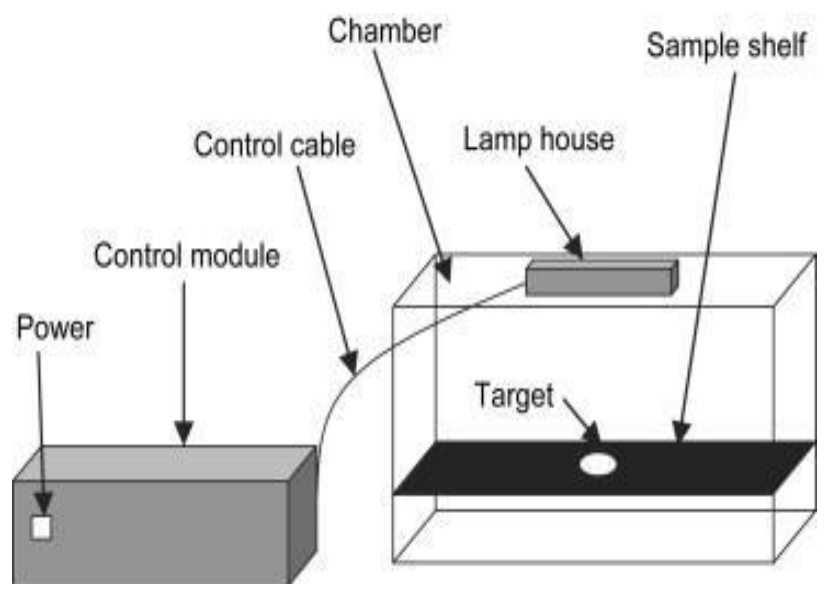




\section{Advantages and limitations}

PL technology is relative fast method of food processing with little or no changes to food quality. It requires low energy input, suitable for dry foods, packaging materials and equipments. Apart from these advantages it has some limitations like only surface effects and therefore difficult to use with complex surfaces, not proven effective against spores, possible resistance in some microorganisms, reliability of equipment to be established and lower penetration depth.

\section{Ultrasound}

\section{Principle of ultrasound}

Sound is vibration that transmitted in a medium and can hear by human ear. The frequency of sound waves audible to human ear ranges from $16 \mathrm{~Hz}$ to $16-20 \mathrm{kHz}$ (Chemat et al., 2011). Sound waves of frequencies less than $20 \mathrm{~Hz}$ are called "Infrasounds" or "Infrasonic's" and the sound waves having frequencies greater than $20 \mathrm{kHz}$ are called "Ultrasounds", "Ultrasonic's" or "Supersonic's". Ultrasounds are classified into two groups, low energy ultrasounds and high energy ultrasound. Low energy ultrasounds have the frequencies greater than $100 \mathrm{kHz}$, low power and low-intensity $(<1$ $\left.\mathrm{W} / \mathrm{cm}^{2}\right)$. These are non-destructive, and uses small power that cannot cause physical or chemical alterations in the materials property and can used for providing information about physicochemical properties of foods like composition, structure and physical state of the food. High energy ultrasound on the other hand have the frequencies $18-100 \mathrm{kHz}$, high power and high-intensity $\left(>1 \mathrm{~W} / \mathrm{cm}^{2}\right)$ (Villamiel and de Jong, 2000). These waves cause physical, mechanical or chemical effects on material and can be used for physical disruption and acceleration of chemical reactions (Awad et al., 2012). When ultrasound waves meet a medium, it creates regions of alternating compression and expansion. These regions of pressure change cause cavitations i.e. formation of bubbles in the medium (Kentish and Feng, 2014). These bubbles are larger in size during the expansion cycle, which increases gas diffusion, causing the bubble to expand. When the ultrasonic energy is insufficient to retain the vapour phase in the bubbles then rapid condensation occurs. The condensed molecules collide and create shock waves. These shock waves create regions of high temperature and pressure. The ability of ultrasound to cause cavitations depends on ultrasound characteristics product properties ambient conditions (Patist and bates, 2008).

\section{Fig.6 Ultrasound}

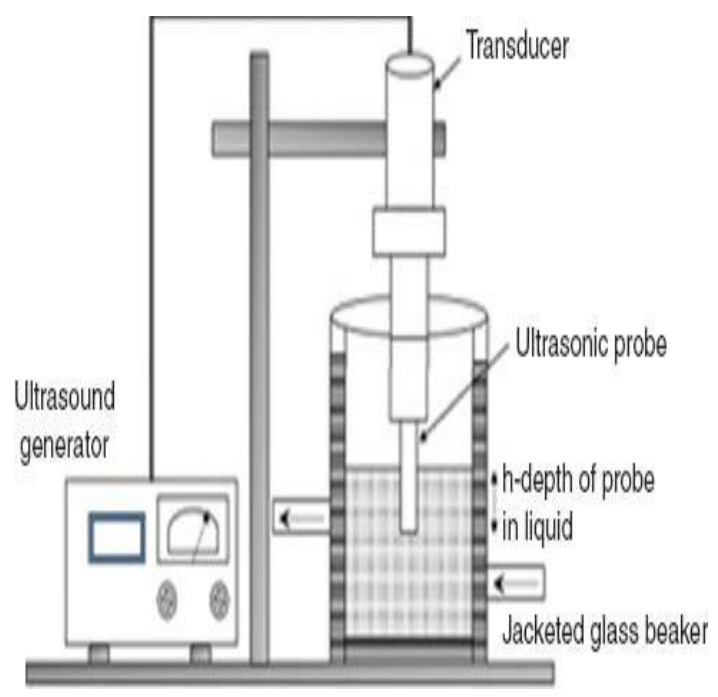

\section{Equipment and applications}

The basic components of ultrasonic systems are power generator, transducer and reactor as shown in Figure 6. Power generator is nothing but the source of electrical power supply. The transducers are the devices used to convert electrical energy, coming from a power generator, into mechanical energy in the form of ultrasonic vibrations. The ultrasonic bath and probe are reactors. Ultrasound has wide 
applications in food industries which include mechanical, chemical and biochemical effects like crystallization (Chow et al., 2003), defoaming, drying, freezing and tenderization of meat (Knorr et al., 2004), extraction (Li et al., 2004), degassing, filtration (Muthukumaran et al., 2006), fermentation (Matsuura et al., 1994), mixing, emulsification/homogenization (Freitas et al., 2006), effluent treatment, enzyme and microbial inactivation, sterilization of equipments etc (Chemat et al., 2011).

\section{Advantages and limitations}

Ultrasounds has many advantages in the processing of food which include its effectiveness against vegetative cells, spores and enzymes, reduced processing times and temperatures, little adaptation required of existing processing plant, increased heat transfer and can be both batch or continuous operation. The limitations of using ultrasound in processing sector are the depth of penetration is affected by solids and air in product, possible damage by free radicals, unwanted modification of food structure and texture may possible, sometimes need to be used in combination with another process like heat or pressure and potential problems with scaling-up plant.

Conventional thermal processing technologies, such as pasteurization, sterilization, drying and evaporation possess the problem of thermal degradation of the food leading to loss of volatile compounds, nutrients, colour, texture and flavour. These methods takes longer processing time therefore require high amount of fuel and energy and are also responsible for environmental pollution as they release combustion gasses by burning fuel during processing. To overcome these problems, modern non thermal processing methods are becoming popular in food industries to increase the production rate and profit. This review is made to study and understand the basic principle, equipments, applications, advantages and limitations of modern nonconventional food processing technologies. These technologies are suitable for processing of almost all the food products particularly for liquid and semi liquid foods and mainly suggested to be used in the large scale food production as they are economical for bulk quantities of foods. Initial cost of investment of these technologies is quit higher than conventional thermal processing methods therefore these technologies are not suited for small scale processing. Commercial adaptation of these technologies is very necessary to maintain nutritional and sensory quality of the product, to save fuel and energy, to avoid environmental pollution, to increase consumer appeal by improving product appearance, to reduce cost of processing, to ensure the availability of food throughout the year and to reduce postharvest losses of agricultural commodities.

\section{References}

Abida, J., B. Rayees, and Masoodi, F. A. 2014. Pulsed light technology: a novel method for food preservation. International Food Research Journal. 21(3): 839-848.

Al-Hilphy, A. R. S. and Ali, H. I. 2013. Milk Flash Pasteurization by the Microwave and Study its Chemical, Microbiological and Thermo Physical Characteristics. J Food Process Technol. 4(7): 250.

Al-Muhtaseb, A. H., W. McMinn, E. Megahey, G. Neill, R. Magee and Rashid, U. 2013. Textural characteristics of microwave-baked and convective-baked madeira cake. J Food Process Technol. 4(2): 209.

Assiry, A. M. 2011. Application of ohmic heating technique to approach near- 
ZLD during the evaporation process of seawater. Desalination. 280(1-3):217223.

Awad, T. S., H. A. Moharram, O. E. Shaltout, D. Asker and Youssef, M. M. 2012. Applications of ultrasound in analysis, processing and quality control of food: A review. Food Research International. 48(2): 410-427.

Bradshaw, S. M., E. J. van Wyk and de Swardt, J. B. 1998. Microwave heating principles and the application to the regeneration of granular activated carbon. The Journal of the South African Institute of Mining and Metallurgy. 201-212.

Buffler, C. R. 1993. Microwave cooking and processing. Engineering fundamentals for the food scientist. New York: Van Nostrand Reinhold.

Campus, M. 2010. High pressure processing of meat, meat products and seafood. Food Engineering Reviews. 2(4). 256273.

Chemat, F., Zill-e-Huma and Khan, M. K. 2011. Applications of ultrasound in food technology: processing, preservation and extraction. Ultrasonics Sonochemistry. 18(4): 813-835.

Chow, R., R. Blindt, R. Chivers and Povey, M. 2003. The sonocrystallization of ice in sucrose solutions: primary and secondary nucleation. Ultrasonics, 41(8): 595-604.

Deeth, H., N. Datta, A. Ross and Dam, X. 2007. Pulsed electric field technology: effect on milk and fruit juices. In G. Tewari and V. Juneja (Eds.), Advances in thermal and non-thermal food preservation. Oxford, UK: Blackwell Publishing.

Dunn, J. E., W. R. Clarck and Asmus, J. F. 1989. Methods of preservation of foodstuffs. Maxwell Laboratories Inc., San Diego, USA. US Patent 4871559.
Duygu, B. and Umit, G. 2015. Application of Ohmic Heating System in Meat Thawing Procedia - Social and Behavioral Sciences. 195 (3): 28222828.

Elamin, W. M., B. J.Endan, Y. A. Yosuf, R. Shamsudin and Ahmedov, A. 2015. High pressure processing technology and equipment evolution: A review. Journal of Engineering Science and Technology Review. 8 (5):75- 83.

Elmanesser, N., S. Guillou, F. Leroi, N. Orange, A. Bakhrouf and Federighi, M. 2007. Pulsed-light system as a novel food decontamination technology: a review. Can. J. Microbiol. 53(7): 813821.

Fellow, P. 2000. Food processing technology principles and poractice. Second eds. In-Processing using electric fields, high hydrostatic pressure, light or ultrasound, Woodhead Publishing Limited and CRC Press LLC. Pp. 210-227.

Freitas, S., G. Hielscher, H. P. Merkle and Gander, B. 2006. Continuous contact and contamination free ultrasonic emulsification- A useful tool for pharmacuetical development and production. Ultrasonics Sonochemistry. 13(1):76-85.

Giese, N. and Darby J. 2000. Sensitivity of microorganisms to different wavelenghts of UV light: implication on modelling of medium pressure UV systems. Water Res. 34(16): 40074013.

Gomez-Lopez, V. M., P. Ragaert, J. Debevere and Devlieghere, F. 2007. Pulsed light for food decontamination: a review. Trends Food Sci. Tech. 18(9): 464-473.

Hawa, L. C. R. I. Putri and Susilo, B. 2011. Pulsed Electric fields pasteurization of milk: Effects of various voltage and treatment time on physical properties. J. Basic. Appl. Sci. Res. 1(10):1516-1523. 
Hill, A and Ilsi. 1998. Europe Microwave Oven Task Force. Microwave Ovens. Brussels: ILSI Europe.

Hite, B H., N. J. Giddings and Weakley, C. E. 1914. Effect of pressure on certain micro-organisms encountered in the preservation of fruits and vegetables. West Virginia University Agricultural Experiment Station, vol. 146, pp. 2-67.

Hite. 1899. The effect of pressure in the preservation of milk. West Virginia University Agricultural Experiment Station. vol. 58, pp. 15-35, 1899.

Hoover, D. G., C. Merick, A. M. Papineau, D. F. Farkas and Knorr, D. 1989. Application of high hydrostatic pressure on foods to inactivate pathogenic and spoilage organisms for extension of shelf life. Food Technology. 43(3): 99107.

Icier, F., H. Yildiz, and Baysal, T. 2006. Peroxidase inactivation and colour changes during ohmic blanching of pea puree. Journal of Food Engineering. 74(3): 424-429.

Kautkar, S. S., J. P. Pandey, A. Singh, A. Kumar and Shukla, A. 2016. Development of ohmic heating apparatus for extraction of rapeseed oil. International Journal for Innovative Research in Science and Technology. 2(11):211-214.

Kautkar, S. S., R. K. Pandey, R. Richa and Kothakota, A. 2015. Temperature dependent electrical conductivities of ginger paste during ohmic heating. International Journal of Agriculture, Environment and Biotechnology. 8(1):21-27.

Kautkar, S. S., R. Richa, and Kothakota, A. 2014. Studies on quality characteristics of ohmically heated ginger paste. Research Journal of Agricultural Sciences. 5(4): 802-805.

Kentish, S and Feng, H. 2014. Applications of power ultrasound in food processing.
Annu. rev. Food Sci. Technol. 5:263284.

Knirsch, M. C., C. A. Santos, A. M. O. S. Vicente, and Penna, T. C. V. 2010. Ohmic heating: a review. Trends in Food Science and Technology. 21(9): 436-441.

Knorr, D., M. Zenker, V. Heinz and Lee, D. U. 2004. Applications and potential of ultrasonics in food processing. Trends in Food Science and Technology. 15(5): 261-266.

Korma, S. A., K. Alahmad, A. H. Ali, M. Shoaib, S. M. Abed, H. Yves, J. N. Atindana and Qin, J. 2016. Application of pulsed electric field technology in apple juice processing. Austin J Nutri Food Sci. 4(2): 1080.

Lakkakula, N. R., M. Lima and Walker, T. 2004. Rice bran stabilization and rice bran oil extraction using ohmic heating. 2004. Bioresource Technology. 92(2):157-161.

Legrand A., J. C. Leuliet, Duquesne, P. Kesteloot, P. Winterton and Fillaudeau, L. 2007. Physical, mechanical, thermal and electrical properties of cooked red ban for continuous ohmic heating process. Journal of Food Engineering, 81(2); 447-458.

Li, H., L. Pordesimo and Weiss, J. 2004. High intensity ultrasound-assisted extraction of oil from soybeans. Food Research International. 37(7): 731-738.

Lule, F. and Koyuncu, T. 2015. Convective and microwave drying characteristics of sorbus fruits (Sorbus domestica L.) Procedia - Social and Behavioral Sciences. 195(3): 2634-2643.

Matsuura, K., M. Hirotsune, Y. Nunokawa, M. Satoh and Honda, K. 1994. Acceleration of cell growth and ester formation by ultrasonic wave irradiation. Journal of Fermentation and Bioengineering. 77(1):36-40. 
McDonald, K. F., R. D. Curry, T. E. Clevenger, K. Unklesbay, A. Eisenstark, J. Golden and Morgen, R. D. 2000. A comparison of pulsed light and continuous ultraviolet light sources for the decontamination of surfaces. IEEE Trans. Plasma Sci. 28(5): 15811587.

Muntean, M. V., O. Marian, V. Barbieru, G. M. Catunescu, O. Ranta I. Drocas and Terhes, S. 2016. High Pressure processing in food industry characteristics and applications. Agriculture and Agricultural Science Procedia 10:377 - 383.

Muthukumaran, S., S. E. Kentish, G. W. Stevens, and Ashokkumar, M. 2006. Application of ultrasound in membrane separation processes: A review. Reviews in Chemical Engineering. 22(3): 155-194.

Ngasri, P. W. and S. K. Sastry. 2016. Tomato peeling by ohmic heating with lye-salt combinations: Effects of operational parameters on peeling time and skin diffusivity. Journal of Food Engineering 186: 10-16.

Nieto, G. M. M., P. D. Pedrow, B. G. Swanson and Barbosa-Canovas G. V. 2003. Energy analysis of liquid whole egg pasteurized by pulsed electric fields. Journal of Food Engineering. 57(3):209-216.

Patist, A. and Bates, D. 2008. Ultrasonic innovations in the food industry: From the laboratory to commercial production. Innovative Food Science and Emerging Technologies. 9(2): 147154.

Puligundla, P., S. A. Abdullah, W. Choi, S. Jun, S. E. Oh and S. Ko. 2013. Potentials of microwave heating technology for select food processing applications - a brief overview and update. J Food Process Technol. 4(11): 278.
Ramesh, M. N., W. Wolf, D. Tevini and Bognar, A. 2002. Microwave Blanching of Vegetables. J Food Sci. 67(1): 390398.

Reddy, M. K. and Penchalaraju, M. 2014. Pulsed electric field technology in food processing industry-a review. International Journal of Science and Research. 3(7): 1144-1149.

Rendueles, E., M. K. Omer, O. Alvseike, C. Alonso-Calleja, R. Capita and Prieto, M. 2011. Microbiological food safety assessment of high hydrostatic pressure processing: A review. LWT - Food Science and Technology. 44(5):12511260.

Sakr, M. and Liu, S. 2014. A comprehensive review on applications of ohmic heating $(\mathrm{OH})$. Renewable and Sustainable Energy Reviews. 39: 262-269.

Sharma, S. K., Q. H. Zhang and Chism, G. W. 1998. Development of a protein fortified fruit beverage and its quality when processed with pulsed electric field treatment. Journal of food quality. 21(6): 459-473.

Sitzmann, W. 1995. High-voltage techniques for food preservation. In W. Gould (Ed.), New Methods of Food Preservation. London, UK: Blackie Academic and Professional.

Stoica, M., L. Mihalcea, D. Borda and Alexe, P. 2013. Non-thermal novel food processing technologies. An overview. Journal of Agroalimentary Processes and Technologies. 19(2): 212-217.

Varghese, K. S., M. C. Pandey, K. Radhakrishna and Bawa, A. S. 2012. Technology, applications and modelling of ohmic heating: a review. J Food Sci Technol. 51(10): 2304-2317.

Vicente, A. and Castro, I. 2007. Novel thermal processing technologies. In $\mathrm{G}$. Tewaria and V. Juneja (Eds.), Advances in thermal and non-thermal food 
preservation. Oxford, UK: Blackwell Publishing.

Villamiel, M. and de Jong, P. 2000. Inactivation of Pseudomonas fluorescensand Streptococcus thermophilus in trypticase soy broth and total bacteria in milk by continuousflow ultrasonic treatment and conventional heating. Food Eng., 45(3): 171- 179 .

Whekof, A. 2000. Disinfection with flash lamp. PDA J. Pharm. Sci. Technol. 54(3): 264-276.

Yasothai, R. and Giriprasad, R. 2015. High intensity pulsed light technology in food processing. International Journal of Science, Environment and Technology. 4(1): 234-236.

Yeom, H. W., G. A. Evrendilek, Z. T. Jin and Zhang Q. H. 2004. Processing of yoghurt based products with pulse electric field microbial, sensory and physical evaluations. J Food Process Preserv. 28: 161-178.

Yordanov, D. G and Angelova, G. V. 2010. High pressure processing for foods preserving. Biotechnol. and Biotechnol. 24(3): 1940-1945.

Zhang, D. and Hamauzu, Y. 2004. Phenolics, ascorbic acid, carotenoids and antioxidant activity of broccoli and their changes during conventional and microwave cooking. Food Chem 88(4): 503-509.

Zhang, Q., G. Barbosa-Canovas and Swanson, B. 1995. Engineering aspects of pulsed electric field pasteurization. Journal of Food Engineering. 25(2): 261-281.

Zhao, W., R. Yang, R. Lu, M. Wang, P. Qian and W. Yang. 2008. Effect of PEF on microbial inactivation and physicalchemical properties of green tea extracts". Food Science and Technology. 41(3): 425-431.

\section{How to cite this article:}

Sheshrao Kautkar and Jai Prakash Pandey. 2018. An Elementary Review on Principles and Applications of Modern Non-Conventional Food Processing Technologies. Int.J.Curr.Microbiol.App.Sci. 7(05): 838-849. doi: https://doi.org/10.20546/ijcmas.2018.705.103 